\title{
Integrin B4, keratinocytes and papillomavirus infection (Review)
}

\author{
MONIKA OLDAK $^{1,2}$, SIGRUN SMOLA-HESS ${ }^{3}$ and RADOSLAW MAKSYM ${ }^{1}$ \\ ${ }^{1}$ Department of Histology and Embryology Center of Biostructure Research, Medical University of Warsaw, \\ Chalubinskiego 5, PL-02004 Warsaw; ${ }^{2}$ Department of Pediatric Diabetology, Neonatology and \\ Birth Defects Medical University of Warsaw, Dzialdowska 1, PL-01-184 Warsaw, Poland; \\ ${ }^{3}$ Institute of Virology, University of Cologne, Fuerst-Pueckler-Str. 56, 50935 Cologne, Germany
}

Received September 13, 2005; Accepted October 27, 2005

\begin{abstract}
Integrin $\beta 4$ is a transmembrane protein expressed predominantly on epithelial cells. In human epidermis integrin $\beta 4$ associates with integrin $\beta 6$. Integrin $\alpha 6 \beta 4$ is concentrated at the basement membrane zone, where it localizes to specialized adhesion structures called hemidesmosomes. In addition to its adhesive functions, keratinocyte integrin $\$ 4$ has been identified as an important regulator of epidermal homeostasis. This review summarizes the current knowledge regarding the role of integrin $\beta 4$ in keratinocyte adhesion, migration, as well as growth and differentiation. Changes in integrin 34 expression in pathological conditions in skin and mucosa, especially those associated with human papillomavirus infection, are described.
\end{abstract}

\section{Contents}

1. Integrins - general features

2. Integrin $B 4$ - genomic and structural organization

3. Integrin $\beta 4$ - expression and hemidesmosome formation

4. Integrin $\beta 4$ - role in keratinocyte adhesion and migration

5. Integrin $\beta 4$ - role in keratinocyte growth and differentiation

6. Integrin $\beta 4$ and human papillomaviruses

\section{Integrins - general features}

Integrins are a family of glycosylated heterodimeric transmembrane adhesion receptors that consist of noncovalently

Correspondence to: Dr Monika Oldak, Department of Histology and Embryology, Center of Biostructure Research, Medical University of Warsaw, Chalubinskiego 5, PL-02004 Warsaw, Poland

E-mail: monika.oldak@ib.amwaw.edu.pl

Key words: integrin, papillomaviruses, E2 protein, keratinocyte, differentiation linked $\alpha$ - and $\beta$-subunits. Most integrins bind to the components of the extracellular matrix, e.g. laminins, collagens, fibronectin, while others bind to counter-receptors of the immunoglobulin-like superfamily (1). The name integrin refers to their function of integrating the cells' exterior, extracellular matrix to the cells' interior, cytoskeleton. Sequencing of the human genome has revealed as many as $24 \alpha$ - and $9 \beta$ subunits (2). Among them are the newly identified $6 \alpha$ - and $1 \beta$ subunits, however, their existence has not yet been firmly established. Currently, 24 functional heterodimers of different composition are known to be generated in humans and expressed on a variety of cell types, i.e. epithelial cells, endothelial cells, fibroblasts, hematopoietic cells, neurons and muscle cells $(1,3)$. In these tissues integrins serve to modulate many aspects of cell behavior, including adhesion, cell shape, motility, survival, proliferation and differentiation. Signals transduced via integrins are essential for embryonic development, tissue regeneration, immune defense and tumor progression.

The combination of the $\alpha$ - and $\beta$-subunits determines the ligand specificity of the integrin. Despite the fact that many integrins have binding specificities for the same ligands, the loss of almost any integrin subunit leads to biological defects in knockout mice. These defects vary from subtle imperfections, as in the $\alpha 1$-knockout mouse to severe abnormalities in several $\alpha$ - or $\beta$-subunit knockout mouse strains, resulting in lethality at embryonic stages or shortly after birth (4-7).

The integrin-stimulated signaling pathways are similar to those triggered by growth factor receptors and are intimately coupled with them (reviewed in ref. 8). Many cellular responses to soluble growth factors, such as epidermal growth factor (EGF), platelet-derived growth factor (PDGF) are dependent on the cells being adherent to a substrate via integrins (4). Additionally to the classical 'outside-in signaling', integrins function as bidirectional signaling receptors. Their activity can also be modulated through a yet incompletely understood 'inside-out signaling' mechanism, which involves the propagation of conformational changes from the cytoplasmic tails across the membrane towards the ligand-binding region (9). Integrins have been described by Hynes (4) as signal transduction receptors, which are at least as significant to cells as more traditional growth factor receptors.

In human epidermis, integrin expression is restricted to the basal layer. It is down-regulated as keratinocytes move through 


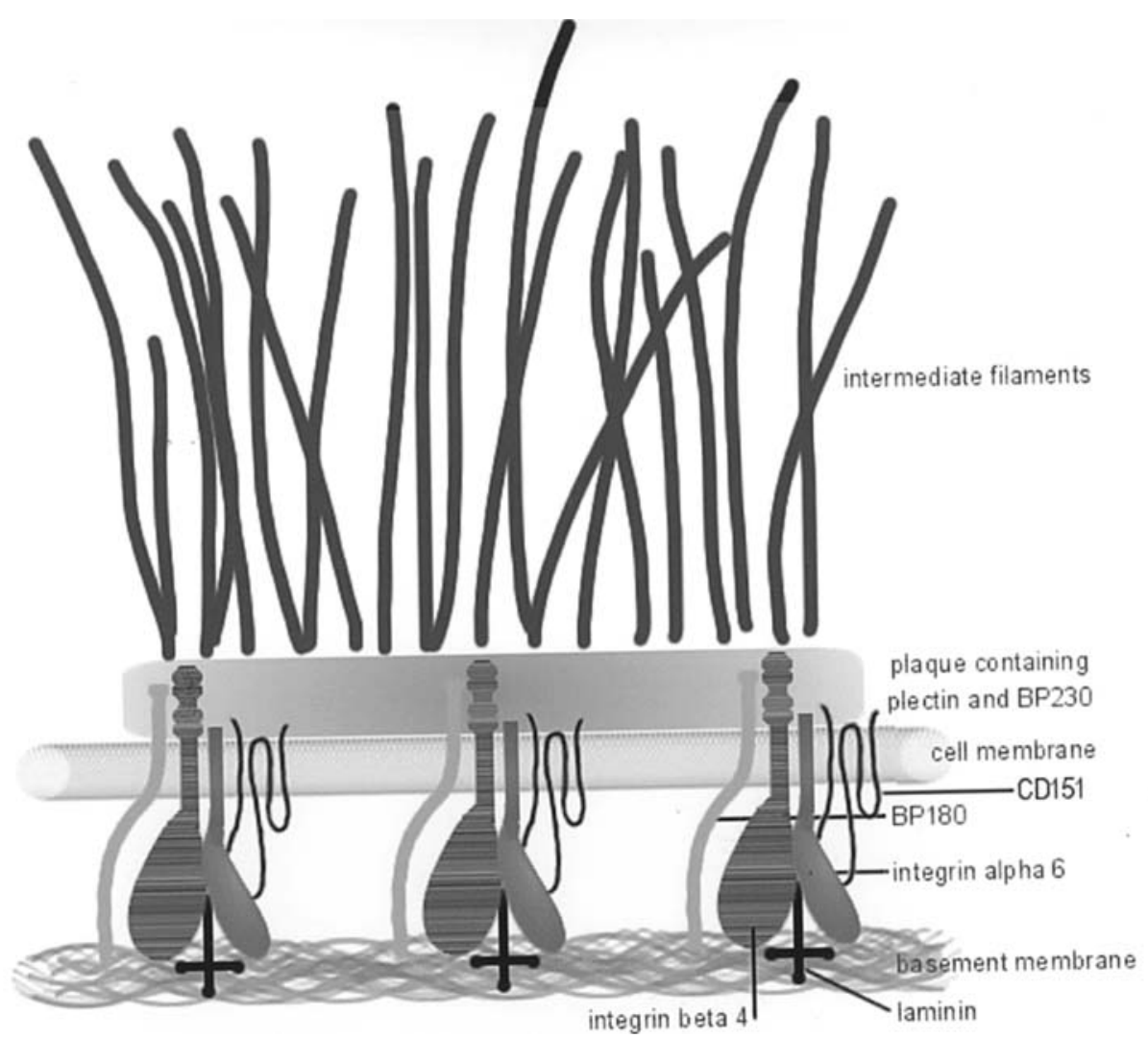

Figure 1. Hemidesmosomes are dense cytoplasmic plaques that mediate the attachment of epidermal cells to the underlying dermis by connecting the extracellular anchoring filaments (laminin) of the basement membrane with the cytoskeletal intermediate filaments. Clusters of integrin $\alpha 6 \beta 4$ form the core of hemidesmosome along with BP180 and tetraspan CD151 protein. Plectin and BP230 belong to the plakin family of proteins and contain intermediate filament-binding domains.

the suprabasal layers and undergo terminal differentiation. The most abundant constitutive integrins in the epidermis are $\alpha 2 \beta 1$, a receptor for collagen, and $\alpha 3 \beta 1$ and $\alpha 6 \beta 4$, receptors for laminins. The $\beta 1$ containing integrins localize to focal contacts and are distributed over the basal, lateral and apical surfaces of basal cells. The $\alpha 6 \beta 4$ integrin is primarily concentrated at the basement membrane zone. It localizes to hemidesmosomes and appears as large patches organized in ring-like structures. In addition to its adhesive functions, integrins in the skin have been identified as important regulators of epidermal homeostasis, influencing the balance between keratinocyte proliferation and differentiation (10-12).

\section{Integrin B4 - genomic and structural organization}

According to the HUGO Gene Nomenclature Committee (www.gene.ucl.ac.uk/nomenclature/) 'integrin B4' is the official name of the protein. Less frequently used alternate names are CD104 antigen or GP150. The human ITGB4 gene is located on chromosome $17 \mathrm{q} 25$. It spans about $28 \mathrm{~kb}$ and contains 41 exons (Genebank acc. no. Y11107) $(13,14)$.

Untranslated DNA sequences in the first exon precede the translated sequences in 5' region. The initiation codon and the amino acid residues of the signal peptide are entirely contained within exon 2. Fifteen exons ranging in size from 24 to $265 \mathrm{bp}$ encode the NH2-terminal extracellular region of the polypeptide composed of 710 amino acids and containing a 4-fold of a cysteine-rich motif similar to those of other integrin $\beta$ subunits and displaying high sequence homology with the epidermal growth factor-calcium-binding motif (EGF-CB) (14).

The short 23-amino-acid transmembrane region is encoded by the 18th exon and the long cytoplasmic tail of the $\mathrm{COOH}$ terminus, approximately 1000 amino acid long, is distributed within the last 23 exons (14-16). The uniquely long intracellular domain of integrin 34 bears no homology with cytoplasmic tail of other $\beta$ subunits (15). It contains binding sites for plectin and bullous pemphigoid antigen 180 (BP180) and two pairs of fibronectin type III-like repeats. Each repeat is encoded by two distinct exons, as in the fibronectin gene.

Most of the known functions of the cytoplasmic tail, such as the localization of $\beta 4$ in the cell membrane and recruitment of plectin, reside in the first pair of fibronectin III domain and the first 36 amino acids of the connecting segment $(17,18)$. The cytoplasmic tail of integrin $\beta 4$ contains also a calx- $\beta$ motif, which is commonly present in the cytoplasmic domain of $\mathrm{Na}-$ $\mathrm{Ca}$ exchangers, where it overlaps domains used for calciumbinding and regulation. Its functional role for integrin $B 4$ remains unclear (19).

The molecular weight of integrin $B 4$ subunit is about $202 \mathrm{kDa}$. In addition to the most common form of integrin ß4, a number of integrin $\beta 4$ variants have been described. Some are generated by proteolytic processing of the mature form of the $B 4$ polypeptide, while others are translated from an alternatively spliced pre-mRNA. For the cytoplasmic 
domain of integrin $B 4$ five (A-E) splicing variants have been described, with $B 4 \mathrm{~A}$ being the most abundant variant. The $\mathrm{B} 4 \mathrm{~B}$ and $\mathrm{B} 4 \mathrm{C}$ contain insertion in the connecting segment of 53 and 70 amino acids, respectively. The $34 \mathrm{D}$ variant carries a $21-\mathrm{bp}$ deletion within intron 38 and $B 4 \mathrm{E}$ has a cytoplasmic domain of only 232 amino acids (20-23).

Integrins $\mathrm{B} 4 \mathrm{~A}$ and $\mathrm{B} 4 \mathrm{~B}$ demonstrated similar ability to associate with hemidesmosomal components. The splice variants $\mathrm{B} 4 \mathrm{~B}$ and $\mathrm{B} 4 \mathrm{C}$ were detected at a constant ratio in a subset of analyzed human tissues (23). Undifferentiated human intestinal crypt cells in contrary to differentiated cells, which express a full length integrin $\mathrm{B} 4 \mathrm{~A}$, express a novel integrin B4A subunit lacking the intracellular $\mathrm{COOH}$-terminal segment. This new variant associates with integrin $\alpha 6$ but is not functional for adhesion to laminin-5 (24). Function and detailed characteristics of these minor $\beta 4$ variants remain to be elucidated.

\section{Integrin B4 - expression and hemidesmosome formation}

Integrin $B 4$ transcription is regulated from a promoter region characterized by a high $\mathrm{G} / \mathrm{C}$ content and lack of TATA and CAAT boxes (25). Data base analysis of the 5'-flanking sequence of the integrin $B 4$ gene revealed the presence of several putative-binding sites for transcription factors, including AP1, Ets, MyoD, NFkB, and Sp1. Functional assays indicated that AP1 and Ets cooperate and activate integrin $\$ 4$ expression. Among the transcription factors comprising AP1, to integrin B4 promoter bound c-Jun, JunB, JunD and a fos family protein, Fra-2 (25). Consistent with the differentiation-specific appearance of various AP1 transcription factors, JunB, JunD and Fra- 2 are all expressed in proliferating basal keratinocytes, where integrin $\beta 4$ is also detected (26).

Additionally, integrin $\$ 4$ expression was shown to be upregulated by EGF or re-expression of integrin $\beta 1$ and downregulated by c-Myc activation and high calcium concentration (27-30). Expression of integrin 34 was also down-regulated by human chorionic gonadotropin (hCG) in human endometrial adenocarcinoma cell line or acute hyperglycaemia in human endothelial cells $(31,32)$. However, the intracellular signaling pathways involved in the regulation of integrin $\$ 4$ expression remain poorly understood.

All cells that express $\beta 4$ also express integrin $\alpha 6$ subunit. Integrin $\beta 4$ associates solely with integrin $\alpha 6$ to form a receptor for most of the known basement membrane laminins, binding to laminin 5 with the highest affinity (33). Integrin $\alpha 634$ is expressed on epithelial cells, such as keratinocytes, endothelial cells and epithelial cells lining the gastrointestinal, respiratory and genitourinary tracts, but also on thymocytes, where its density parallels thymocyte maturation. Expression of integrin a6ß4 was also detected on Schwann cells and fibroblast in the peripheral nervous system, where the $\alpha 6 \beta 4$ is involved in ensheathment and myelination of axons (34-38). Integrin $\alpha 6 \beta 4$ has also been found on human first-trimester trophoblast and term placenta (39). During embryonic development and differentiation, integrin $\alpha 6 \beta 4$ plays an important role in tissue and organ morphogenesis (40-43).

In epithelia, $\alpha 6 \beta 4$ is typically concentrated at the ventral surface of the cells opposed to the basal membrane zone in specialized adhesion structures, called hemidesmosomes
(Fig. 1). They are implicated in the stable attachment of the basal cells to the underlying basement membrane by connecting the intermediate keratin filaments with the extracellular matrix. Based on structural constituents, two subtypes of hemidesmosomes are distinguished. Type I or classical hemidesmosomes are present in basal keratinocytes of stratified squamous epithelia. At the core of the hemidesmosome is a6ß4 integrin, accompanied by cytoplasmic proteins, such as plectin, bullous pemphigoid antigen 180 (BP 180), transmembrane bullous pemphigoid antigen 230 (BP 230) and tetraspanin CD151 (44-46). Type II hemidesmosomes also termed hemidesmosome-like structures contain only $\alpha 6 \beta 4$ and plectin and are found in simple epithelia and cultured epithelial cells $(47,48)$.

Intracellularly, integrin $\beta 4$ interacts with the intermediate filament system, i.e. keratin filaments in epidermal cells or vimentin filaments in endothelial cells $(49,50)$. In vitro, $\alpha 6 ß 4$ is also found on the leading lamellae of a migrating cell in association with filamentous actin (51).

\section{Integrin $\$ 4$ - role in keratinocyte adhesion and migration}

Generation of mice lacking $B 4$ integrin underscored its importance in cell adhesion to the underlying basement membrane. Mice with targeted deletion of the $\beta 4$ subunit died shortly after birth and displayed extensive detachment of the epidermis and other epithelia normally expressing $\alpha 6 ß 4$. The effect was most pronounced in the gastrointestinal tract $(40,41)$. When integrin $\beta 4$ was missing, $\alpha 6$ integrin was barely detectable in mouse skin, suggesting that in the absence of $\beta 4, \alpha 6$ is unstable. Hemidesmosomes were completely absent in the $\beta 4$ null mouse keratinocytes and despite the presence of other components of hemidesmosomes such as BP180 and BP230, the keratin filaments failed to attach to the basal membrane $(40,41)$.

Humans who have mutations in $\beta 4$ integrin gene develop junctional epidermolysis bullosa with pyloric atresia (JEB-PA), an autosomal recessive disorder with a high mortality rate. In addition to severe blistering at the dermo-epidermal junction in epidermolysis bullosa with pyloric atresia, recurrent erosions occur in the gastrointestinal and genitourinary tracts as well as in the cornea and the respiratory tract (52).

Patients with the lethal variant of the disorder usually have mutations leading to premature termination of integrin 34 , whereas missense mutations rather lead to nonlethal phenotypes (53). Immunofluorescent studies of affected skin revealed negative staining for integrin $\beta 4$ in lethal cases and positive but attenuated staining in nonlethal cases (53). The phenotype is strongly influenced by the position of the mutation in the protein functional domains. Lethal variant of JEB-PA has been described in a patient with homozygous in-frame 33-bp deletion in the ITGB4 gene. It has been hypothesized that the deletion interferes with folding of the mutated protein leading to its rapid degradation (54).

Recently, a 2 bp-deletion encompassing the third fibronectin III repeat in the cytoplasmic domain of integrin $\$ 4$ was shown to be clinically pathogenic and manifested by the predominant features of epidermolysis bullosa simplex (EBS) (55).

Analyses of the human and mice tissues lacking integrin $\beta 4$ indicated that other epidermal integrins seem unable to 


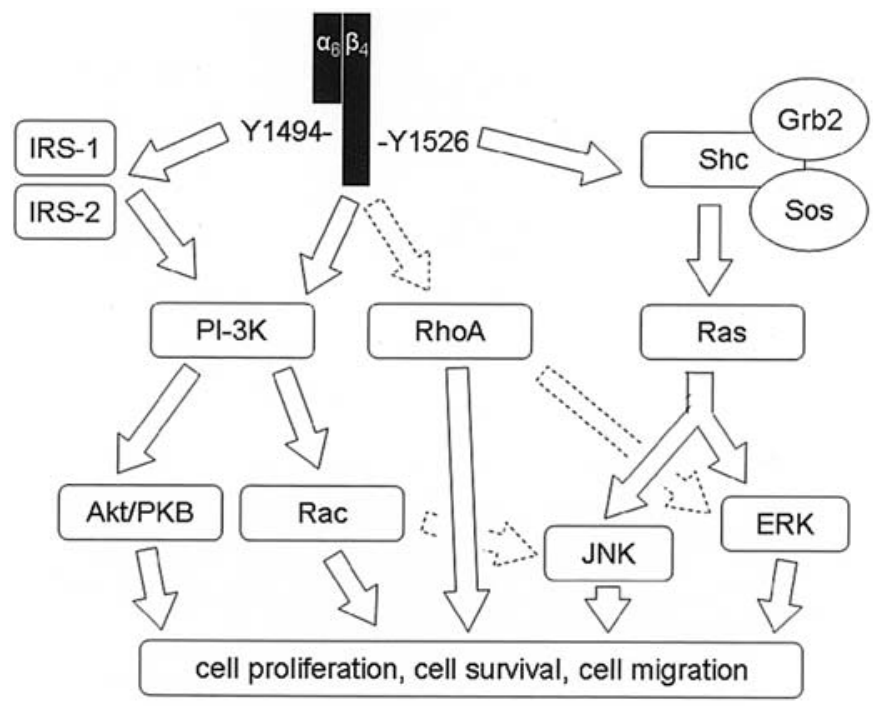

Figure 2. Integrin $\alpha 6 \beta 4$ signaling. Details in text.

compensate for the loss of $\alpha 6 \beta 4$ in providing the strong cellsubstratum adhesion necessary to anchor the epidermis to the skin. The weak adhesion that does occur in the absence of $\alpha 6 \beta 4$ is most likely attributable to integrin heterodimers containing integrin $B 1$ subunit, but this is not sufficient to withstand the extensive traumas to which the skin is routinely subjected.

Recent studies have demonstrated a novel and apparently contrasting function for integrin $\alpha 634$ in the migration of epithelial cells. These findings revealed that in response to migratory stimuli, hemidesmosomes are disassembled and integrin $\alpha 6 \beta 4$ associates with filamentous actin and localizes at the leading edge of a migrating cell in actin protrusions. It has been shown that integrin $\beta 4$ has the ability to promote formation and stabilization of the membrane protrusions associated with migration, as antibody-specific for $\alpha 6 ß 4$ inhibited the formation of filopodia and lamellipodia and inhibited cell migration (51). The observation that $\alpha 6 \beta 4$ interacts with actin filaments suggested that it could transmit forces to the substrate generated by the acto-myosin system. This hypothesis was confirmed by the results of traction-force detection assays, indicating that the traction forces were exerted directly through $\alpha 6 \beta 4$ in cells plated on laminin or on anti $\alpha 6 \beta 4$-antibody, without the need to engage other integrins. The a6ß4-dependent forces were organized into the compression machine localized at the base of lamellae. Thus, in this way integrin $\alpha 634$ may remodel the basement membrane components and this ability of $\alpha 6 \beta 4$ could have important implications for the mechanism of cell migration and invasion (56).

Recently, it has become clear that self-association of the 34 cytoplasmic domains is capable of ligand-independent signal transduction influencing migration of carcinoma cells. This possibility implies that $\beta 4$ signaling is not strictly limited to a specific matrix environment and might also occur on nonlaminin substrates. In these cases, integrin $\beta 4$ might be phosphorylated after activation of the cells by growth factors (51).

The central molecule regulated by $\beta 4$ and implicated in epithelial motility is phosphatidylinositol 3'-kinase (PI-3K). In breast carcinoma cell lines, activation of PI-3K by integrin $\alpha 634$ took place in cells expressing also erbB2, a receptor of the EGFR family. This finding indicated that cooperation of integrin $\alpha 6 \beta 4$ with a specific growth factor receptor is required for PI-3K activation. Alternatively, activation of PI-3K was shown to involve the insulin receptor substrates (IRS-1 and IRS-2) and the tyrosine residue (Y1494) located at the third fibronectin type III repeat of integrin $\beta 4$ cytoplasmic tail (Fig. 2) $(51,57)$. Activation of PI-3K by $\alpha 6 \beta 4$ may stimulate the function of other integrins, especially $\alpha 3 \beta 1$, that are important for epithelial migration. Additional signaling pathways by which $\alpha 6 \beta 4$ stimulates cell migration are mitogenactivated protein kinase (MAPK) and Rac and RhoA GTPases $(51,57)$.

Integrin $\beta 4$ was initially identified as a tumor-associated antigen (TS180) associated with metastasis. However, given its widely known function of mediating adhesive contacts in epithelia, this role of integrin $\beta 4$ was long not anticipated (58). Expression of integrin $\beta 4$ is maintained or even increased in several types of invasive and metastatic carcinoma and the expression level often correlates with tumor aggressiveness (57). In the skin, an association between enhanced 34 integrin expression and tumor progression has been demonstrated for squamous cell carcinoma $(59,60)$. In a usually non-metastatic basal cell, carcinoma of the skin 34 integrin expression is reduced $(61,62)$.

\section{Integrin B4, role in keratinocyte growth and differen- tiation}

Several observations indicate that $\alpha 634$ integrin is implicated in transducing signals from the extracellular matrix that do not only control the cytoskeleton organization and assembly of hemidesmosomes but also influence cell proliferation, survival and differentiation (63). In normal undamaged epidermis the expression of $\alpha 634$ is restricted to the basal cell layer, which contains cells endowed with proliferative capacity $(10,34)$. As cells leave the basal layer, hemidesmosomes disappear and no integrins are expressed (12). It is also known that epidermal stem cells are more adhesive to the extracellular matrix than their transit-amplifying daughter cells, committed to differentiation (64). Thus, the restricted integrin ß4 expression pattern implies its involvement in the regulation of cell proliferation.

Keratinocytes exit the cell cycle and begin their differentiation program when they detach from the basement membrane to migrate to the upper epidermal layers (65). This process could be replicated in vitro by depriving cultured keratinocytes of anchorage to their endogenously produced matrix, which is rich in laminin-5, a ligand for $\alpha 6 \beta 4$ integrin (66).

A proposed $\alpha 634-$ mediated signaling cascade affecting keratinocyte proliferation seems to lead via the activation of Ras-MAPK pathways. Activation of $\alpha 6 \beta 4$ in response to ligation and adhesion leads to recruitment of Shc, Grb2 and Sos, activation of Ras and stimulation of the MAPK, Jnk and Erk signaling cascades (67). The tyrosine residue (Y1526) located in the third fibronectin type III repeat of integrin 34 was reported to be the binding site for Shc (Fig. 2) (51).

Signaling through $\alpha 634$ has also been proposed to be independent of its adhesive functions due to its ability to 
interact with activated receptor tyrosine kinases, i.e. EGF receptor or Met. In this model the cytoplasmic domain of integrin $\beta 4$ becomes phosphorylated by the activated receptors and serves as an amplifier of their mitogenic and motogenic signals (reviewed in ref. 68).

The primary effect of complete $\beta 4$ integrin deletion is massive epidermal blistering associated with degeneration. The epidermal regions that remain attached to the basement membrane also contained cells presenting signs of degeneration similar to those described when keratinocytes could not adhere to their substratum (40). These data implied that survival of mitotically active cells of stratified squamous epithelia is dependent upon B4 integrin, whereas its lack makes the cells susceptible to degeneration.

Furthermore, Murgia et al (69) found that keratinocytes from mouse embryos carrying a targeted deletion of the cytoplasmic tail of the $\beta 4$ subunit display a significant proliferative defect. However, according to Di Persio et al (70) decrease of keratinocyte proliferation was not observed in B4-null embryos.

In addition, Raymond et al (71) have recently shown using a conditional knockout mouse strain, in which the integrin $\beta 4$ gene was inactivated only in small stretches of skin, that epidermal differentiation and proliferation was normal in the absence of integrin $\alpha 634$ provided that cell adhesion was not compromised. They concluded that there is no evidence for a role of $\alpha 6 \beta 4$ integrin in controlling cell proliferation and survival which is independent of its adhesive function (71).

In human hyperproliferative skin pathologies, for example during wound healing, in psoriatic lesions or in squamous cell carcinoma, integrins have an aberrant expression pattern and beside the basal cell layer appear also in suprabasal differentiating cells (11). Recently, it has been demonstrated that the suprabasal $\alpha 6 \beta 4$ expression has positive influence on the susceptibility of keratinocytes to chemical carcinogenesis. In response to treatment with a phorbol ester tumor promoter, the suprabasal $\alpha 6 \beta 4$ integrin enhanced the proliferative response of basal cells leading to the formation of papillomas and carcinomas. The effect of suprabasal $\alpha 6 \beta 4$ on cell proliferation involved disruption of TGF- $\beta$-mediated growth inhibition by suppressing nuclear translocation of activated Smad2/3 proteins. It has been shown that for the inhibition of TGF- $\beta$ signaling suprabasal $\alpha 6 \beta 4$ integrin required PI-3K activity and E-cadherin-mediated cell-cell adhesion (72).

In case of carcinoma cells, $\alpha 634$-mediated signals appear to have different effects on cell behavior depending on the cell type and their differentiation status. For example, in a keratinocyte-derived A431 human epidermoid carcinoma cell line activation of $\alpha 6 \beta 4$ with a monoclonal antibody directed against $B 4$ protected the cells from apoptosis through activation of PI-3K and Akt kinase signaling pathway (73). In squamous cell carcinoma-derived HPV-18 positive HeLa cells ligation of $\alpha 6 \beta 4$ by laminin 5 promoted transcription from the fos serum response element and cell proliferation (67). Similarly, expression of $\alpha 6 \beta 4$ on epithelial cells lines derived from colon, breast and thyroid carcinomas positively correlated with proliferation. On the contrary, expression of the $\beta 4$ subunit in the rectal or gastric carcinoma cells was associated with apoptosis induction (reviewed in ref. 74).

\section{Integrin $\$ 4$ and human papillomaviruses}

Human papillomaviruses (HPVs) induce a wide spectrum of epithelial proliferative lesions ranging from benign warts to invasive carcinoma (75). The targets of HPV infection are stratified epithelia at different anatomical sites. According to the preferred site of tropism, two categories of HPV can be distinguished, the cutaneous HPVs and the mucosal HPVs. The latter primarily infect epithelia of anogenital region, oral cavity or upper respiratory tract (76).

Infection by HPVs is believed to occur through microtraumas in the stratified epithelium, exposing the basal cells to entry for viruses. The receptor for HPV entry has not been functionally identified. However, the $\alpha 6$ integrin complexed with either $\beta 1$ or $\beta 4$ integrin has been proposed to be the HPV receptor (77). During wound healing, expression of integrins is up-regulated in epithelial cells, which makes them good candidates. Nevertheless, it should be underlined that no functional studies have yet shown the $\alpha 6 \beta 1$ or $\alpha 6 \beta 4$ integrins to mediate HPV entry.

Most lesions induced by HPVs in immunocompetent individuals are benign warts, which display self-limited growth and usually regress, spontaneously or after treatment (78). On the contrary, infection with cutaneous HPV types, i.e. HPV5 and HPV8 is associated with the development of skin carcinoma in patients suffering from an inherited skin disease, epidermodysplasia verruciformis (EV) $(79,80)$.

Furthermore, specific mucosal HPV types play a central role in anogenital carcinogenesis, especially in carcinoma of the uterine cervix, the second leading cause of cancer-related deaths in women worldwide (81). Approximately $80 \%$ of cervical cancers are associated with four HPV types, i.e. HPV16, 18, 31 and 45 (82). Oncogenic genital HPV types, especially HPV type 16 , are also causally associated with a fraction of vaginal, vulvar, penile, and anal cancers (83).

In vitro study of HPV16 oncogene E6/E7-immortalized esophageal keratinocytes revealed a lower level of integrin $\beta 4$ in these cells. Reduced expression of $\beta 4$ integrin led to more rapid proliferation and anchorage-independent growth potential, which was interpreted by the authors as a critical step in malignant progression (84).

In situ studies of vulvar warts and neoplasia of the uterine cervix gave different results. In vulvar warts associated with HPV infection up-regulation of integrin $\beta 4$ expression was detected. In these lesions, expression of $\beta 4$ integrin was found at the periphery of basal cells, in epibasal and spinous layers of warts (85).

Immunohistochemical analysis of integrin $\beta 4$ expression pattern in cervical intraepithelial neoplasia revealed its presence in the upper cell layers of cervical epithelium. The extent of extrabasal staining for integrin $\beta 4$ corresponded with the grade of cervical intraepithelial neoplasia (CIN) $(86,87)$. Similar results were obtained in HPV-associated cervical intraepithelial neoplastic lesions. In this study, high expression of integrin $B 4$ was found in HPV16-associated CIN III and invasive tumors as compared with low integrin $\beta 4$ levels in CIN I and II (88). In the analyzed lesions, expression of integrin $\beta 4$ reversely correlated with the presence of viral E2 transcripts.

The papillomavirus E2 protein is a transcription factor involved in regulation of viral replication and transcription. 
E2 functions predominantly as a repressor of viral E6, E7 oncogene expression in the mucosal high risk HPVs. The E2 open reading frame is disrupted in HPV-induced cervical carcinoma as a result of viral genome integration into the cellular genome. Loss of E2 leads to up-regulation of viral oncogene E6 and E7 transcription, an event considered to play a key role in cellular transformation (89).

Recently, we have found that the E2 protein from cutaneous HPV8 and mucosal high risk HPV18 is an important regulator of human integrin 34 expression. Expression of HPV8 or HPV18 E2 protein in human keratinocytes led to a dosedependent reduction of integrin $\beta 4$ expression. In case of HPV8 E2, the suppression at least partially resulted from direct interactions between E2 and the human integrin $B 4$ promoter (90).

We hypothesized that in papillomavirus infection, downregulation of integrin 34 may provide a signal inducing differentiation and enabling the virus to begin its productive life cycle, which takes place exclusively in the suprabasal layers of stratified epithelia. Loss of E2 expression as a result of progression of HPV-induced lesions towards malignancy may lead to deregulation of integrin $\beta 4$ expression and its appearance in the suprabasal layers. The mechanism involved in the aberrant expression pattern of integrin $\beta 4$ as shown for high grade CIN lesions (88) still has to be defined.

\section{Acknowledgements}

M.O. is the recipient of a Young Scientist Stipend from the Foundation for Polish Science. This study was supported by Warsaw Medical University Grant No. 1M15/WB3/ 2005.

\section{References}

1. Van der Flier A and Sonnenberg A: Function and interactions of integrins. Cell Tissue Res 305: 285-298, 2001.

2. Venter JC, Adams MD, Myers EW, Li PW, Mural RJ and Sutton GG, et al: The sequence of the human genome. Science 291: 1304-1351, 2001.

3. Danen EH and Sonnenberg A: Integrins in regulation of tissue development and function. J Pathol 201: 632-641, 2003.

4. Hynes RO: Integrins: bidirectional, allosteric signaling molecules. Cell 110: 673-687, 2002.

5. Brakebusch C, Hirsch E, Potocnik A and Faessler R: Genetic analysis of beta 1 integrin function: confirmed, new and revised roles for a crucial family of cell adhesion molecules. J Cell Sci 110: 2895-2904, 1997.

6. Darribere T, Skalski M, Cousin HL, Gaultier A, Montmory C and Alfandari D: Integrins: regulators of embryogenesis. Biol Cell 92: 5-25, 2000.

7. Holtkotter O, Nieswandt B, Smyth N, Muller W, Hafner M, Schulte V, Krieg T and Eckes B: Integrin alpha 2-deficient mice develop normally, are fertile, but display partially defective platelet interaction with collagen. J Biol Chem 277: 1078910794, 2002.

8. Schwartz MA: Integrin signaling revisited. Trends Cell Biol 11: 466-470, 2001

9. Liddington RC and Ginsberg MH: Integrin activation takes shape. J Cell Biol 158: 833-839, 2002.

10. Adams JC and Watt FM: Expression of $\beta 1, \beta 3, \beta 4$ and $B 5$ integrins by human epidermal keratinocytes and nondifferentiating keratinocytes. J Cell Biol 115: 829-841, 1991.

11. Watt FM and Hertle MD: Keratinocyte integrins. In: The Keratinocyte Handbook. Leigh IM, Lane EB and Watt FM (eds). Cambridge University Press, Cambridge, pp153-164, 1994.

12. Fuchs E, Dowling J, Segre J, Lo SH and Yu Q-Ch: Integrators of epidermal growth and differentiation: distinct functions for $\beta 1$ and $B 4$ integrins. Current Opin Genet Dev 7: 672-682, 1997.
13. Hogervorst F, Kuikman I, Geurts van Kessel A and Sonnenberg A: Molecular cloning of the human alpha- 6 intergrin subunit: alternative splicing of alpha- 6 and mRNA and chromosomal localization of the alpha- 6 and beta- 4 genes. Eur J Biochem 199: 425-433, 1991.

14. Iacovacci S, Gagnoux-Palacios L, Zambruno G, Meneguzzi G and D'Alessio M: Genomic organization of the beta 4 integrin gene. Mamm Genome 8: 448-450, 1997.

15. Hogervorst F, Kuikman I, von dem Borne AE and Sonnenberg A: Cloning and sequence analysis of beta-4 cDNA: an integrin subunit that contains a unique $118 \mathrm{kd}$ cytoplasmic domain. EMBO J 9: 765-770, 1990.

16. Suzuki S and Naitoh Y: Amino acid sequence of a novel integrin-beta 4 subunit and primary expression of the mRNA in epithelial cells. EMBO J 9: 757-763, 1990.

17. Mainiero F, Pepe A, Wary KK, Spinardi L, Mohammadi M, Schlessinger J and Giancotti FG: Signal transduction by the alpha 6 and beta 4 integrin: distinct beta 4 subunit sites mediate recruitment of Shc/Grb2 and association with the cytoskeleton of hemidesmosomes. EMBO J 14: 4470-4481, 1995.

18. Niessen CM, Hulsman EHM, Oomen LCJM, Kuikman I and Sonnenberg A: A minimal region on the integrin B4 subunit that is critical to its localization in hemidesmosomes regulates the distribution of HD1/plectin in COS-7 cells. J Cell Sci 110: 1705-1716, 1997.

19. May AP and Ponting CP: Integrin alpha- and beta 4-subunitdomain homologues in cyanobacterial proteins. Trends Biochem Sci 24: 12-13, 1999

20. Tamura RN, Rozzo C, Starr L, Chambers J, Reichardt LF, Cooper HM and Quaranta V: Epithelial integrin alpha6 beta4: complete primary structure of alpha6 and variant forms of beta4. J Cell Biol 111: 1593-1604, 1990.

21. Giancotti FG, Stepp MA, Suzuki S, Engvall E and Ruoslahti E: Proteolytic processing of endogenous and recombinant beta4 integrin subunit. J Cell Biol 118: 951-959, 1992.

22. De Melker AA and Sonnenberg A: Integrins: Alternative splicing as a mechanism to regulate ligand binding and integrin signaling events. Bioessays 21: 499-509, 1999.

23. Micheloni A, Falcioni R, Zambruno G and D'Alessio M: The human integrin $B 4 \mathrm{~B}$ and $\mathrm{B} 4 \mathrm{C}$ variants are not expressed in a tissue-specific manner. FEBS Lett 519: 238-239, 2002

24. Basora N, Herring-Gillam FE, Boudreau F, Perreault N, Pageot LP, Simoneau M, Bouatrouss Y and Beaulieu JF: Expression of functionally distinct variants of the beta(4). A integrin subunit in relation to the differentiation state in human intestinal cells. J Biol Chem 274: 29819-29825, 1999.

25. Takaoka AS, Yamada T, Gotoh M, Kanai Y, Imai K and Hirohashi S: Cloning and characterization of the human B4integrin gene promoter and enhancers. J Biol Chem 273: 33848-33855, 1998.

26. Welter JF and Eckert RL: Differential expression of the fos and jun family members c-fos, fosB, Fra-1, Fra-2, c-jun, junB and junD during epidermal keratinocytes differentiation. Oncogene 11: 2681-2687, 1995.

27. Song QH, Gong H and Trinkaus-Randall V: Role of epidermal growth factor and epidermal growth factor receptor on hemidesmosome complex formation and integrin subunit beta 4 . Cell Tissue Res 312: 203-220, 2003.

28. Sun H, Santoro SA and Zutter MM: Downstream events in mammary gland morphogenesis mediated by re-expression of the alpha 2 beta 1 integrin: the role of the alpha 6 and beta 4 integrin subunits. Cancer Res 58: 2224-2233, 1998

29. Frye M, Gardner C, Li ER, Arnold I and Watt FM: Evidence that Myc activation depletes the epidermal stem cell compartment by modulating adhesive interactions with the local microenvironment. Development 130: 2793-2808, 2003.

30. Carey TE, Laurikainen L, Nair TS, Reinke TS, Coling DE, Wolf GT, van Waes C, Liebert M and Marcelo C: Regulation of expression and phosphorylation of A9/alpha6 beta4 integrin in normal and neoplastic keratinocytes. J Natl Cancer Inst Monogr: 75-86, 1992.

31. Kayisli UA, Korgun ET, Akkoyunlu G, Arici A and Demir R: Expression of integrin alpha5 and integrin beta4 and their extracellular ligands and laminin in human deciduas during early pregnancy and its steroid-mediated regulation. Acta Histochemica 107: 173-185, 2005.

32. Chettab K, Zibara K, Belaiba SR and Mc Gregor JL: Acute hyperglcaemia induces changes in the transcription levels of 4 major genes in human endothelial cells: microarrays-based expression analysis. Thromb Haemost 87: 141-148, 2002. 
33. Lee EC, Lotz MM, Steele GD Jr and Mercurio AM: The integrin alpha 6 beta 4 is a laminin receptor. J Cell Biol 117: 671-678, 1992.

34. Kajiji S, Tamura RN and Quaranta V: A novel integrin $(\alpha E \beta 4)$ from human epithelial cells suggests a fourth family of integrin adhesion receptors. EMBO J 8: 673-680, 1989.

35. Kennel SJ, Godfrey V, Cháng LY, Lankford TK, Foote LJ and Makkinje A: The $B 4$ subunit of the integrin family is displayed on a restricted subset of endothelium in mice. J Cell Sci 103 . 145-150, 1992.

36. Watt SM, Thomas JA, Edwards AJ, Murdoch SJ and Horton MA: Adhesion receptors are differentially expressed on developing thymocytes and epithelium in human thymus. Exp Hematol 20: 1101-1111, 1992

37. Niessen CM, Cremona O, Daams H, Ferraresi S, Sonnenberg A and Marchiso PC: Expression of the integrin alpha 6 beta 4 in peripheral nerves: localization in Schwann and perineural cells and different variants of the beta 4 subunit. J Cell Sci 107: 543-552, 1994

38. Vivinus-Nebot M, Ticchioni M, Mary F, Hofman P, Quaranta V, Rousselle P and Bernard A: Laminin 5 in the human thymus: control of $\mathrm{T}$ cell proliferation via alpha6beta4 integrins. J Cell Sci 144: 563-574, 1999

39. Aplin JD: Expression of integrin alpha 6 beta 4 in human trophoblast and its loss from extravillous cells. Placenta 14: 203-215, 1993

40. Dowling J, Yu Q-C and Fuchs E: Beta 4 integrin is required for hemidesmosome formation, cell adhesion and cell survival. J Cell Sci 134: 559-572, 1996.

41. Van der Neut R, Krimpenfort P, Calafat J, Niessen CM and Sonnenberg A: Epithelial detachment due to absence of hemidesmosome in integrin beta 4 null mice. Nature Genet 13: 366-369, 1996.

42. Perreault N, Vachon PH and Beaulieu JF: Appearance and distribution of laminin A chain isoforms and integrin alpha 2 , alpha 3 , alpha 6 , beta 1 , and beta 4 subunits in the developing human small intestine mucosa. Anat Rec 242: 242-250, 1995

43. Coraux C, Meneguzzi G, Rousselle P, Puchelle E and Gaillard D: Distribution of laminin 5, integrin receptors, and branching morphogenesis during normal human fetal lung development. Dev Dyn 225: 176-185, 2002

44. Borradori L and Sonnenberg A: Structure and function of hemidesmosomes: more than simple adhesion complexes. J Invest Dermatol 112: 411-418, 1999.

45. Sterck LMTH, Geuijen CAW, Oomen LCJM, Calafat J Janssen H and Sonnenberg A: The tetraspan molecule CD151, a novel constituent of hemidesmosomes, associates with the integrin alpha6beta4 and may regulate the spatial organization of hemidesmosomes. J Cell Biol 149: 969-982, 2000.

46. Koster J, Geerts D, Favre B, Barradori L and Sonnenberg A: Analysis of the interactions between BP180, BP230, plectin and the integrin alpha 6 beta 4 important for hemidesmosome assembly. J Cell Sci 116: 387-399, 2003.

47. Uematsu J, Nishizawa Y, Sonnenberg A and Owaribe K: Demonstration of type II hemidesmosomes in a mammary gland epithelial cell line, BMGE-H. J Biochem 115: 469-476, 1994.

48. Geuijen CAW and Sonnenberg A: Dynamics of the $\alpha 6 \beta 4$ integrin in keratinocytes. Mol Cell Biol 13: 3845-3858, 2002.

49. Hopkins SB and Jones JC: The N terminus of the transmembrane protein BP180 interacts with the N-terminal domain of BP230, thereby mediating keratin cytoskeleton anchorage to the cell surface at the site of hemidesmosome. Mol Biol Cell 11: 277-286, 2000.

50. Homan SM, Martines R, Benware A and LaFlamme SE: Regulation of the association of alpha 6 beta 4 with vimentin intermediate filaments in endothelial cells. Exp Cell Res 281: 107-114, 2002.

51. Mercurio AM, Rabinovitz I and Shaw LM: The $\alpha 6 ß 4$ integrin and epithelial cell migration. Curr Opin Cell Biol 13: 541-545, 2001.

52. Ashton GH, Sorelli P, Mellerio JE, Keane FM, Eady RA and McGrath JA: $\alpha 6 \beta 4$ integrin abnormalities in junctional epidermolysis bullosa with pyloric atresia. Br J Dermatol 144: 408-414, 2001

53. Nakano A, Pulkkinen L, Murrell D, Rico J, Lucky AW, Garzon M, Stevens CA, Robertson S, Pfendner E and Uitto J Epidermolysis bullosa with congenital pyloric atresia: novel mutations in the beta-4 integrin gene (ITGB4) and genotype/ phenotype correlations. Pediat Res 49: 618-626, 2001
54. Micheloni A, De Luca N, Tadini G, Zambruno G and D'Alessio M: Intracellular degradation of beta4 integrin in lethal junctional epidermolysis bullosa with pyloric atresia. Br J Dermatol 151: 796-802, 2004.

55. Jonkman MF, Pas HH, Nijenhuis M, Kloosterhuis G and Steege G: Deletion of a cytoplasmic domain of integrin beta4 causes epidermolysis bullosa simplex. J Invest Dermatol 119: 1275-1281, 2002

56. Rabinovitz I, Gipson IK and Mercurio AM: Traction forces mediated by $\alpha 634$ integrin: implications for basement membrane organization and tumor invasion. Mol Biol Cell 12: 4030-4043, 2001

57. Mercurio AM and Rabinovitz I: Towards a mechanistic understanding of tumor invasions - lessons from the $\alpha 6 \beta 4$ integrin. Semin Cancer Biol 11: 129-141, 2001.

58. Falconi R, Sacchi A, Reseau J and Kennel SJ: Monoclonal antibody to human carcinoma-associated protein complex: quantitation in normal and tumor tissue. Cancer Res 48: 816-821, 1988.

59. Tennenbaum T, Weiner AK, Belanger AJ, Glick AB, Hennings H and Yuspa SH: The suprabasal expression of alpha 6 and beta 4 integrin is associated with a high risk for malignant progression in mouse skin carcinogenesis. Cancer Res 53: 4803-4810, 1993.

60. Van Waes C, Kozarsky KF, Warren AB, Kidd L, Paugh D Liebert $M$ and Carey TE: The A9 antigen associated with aggressive human squamous carcinoma is structurally and functionally similar to newly defined integrin alpha 6 beta 4 . Cancer Res 51: 2395-2402, 1991.

61. Sollberg S, Peltonen J and Uitto J: Differential expression of laminin isoforms and beta 4 integrin epitopes in the basement membrane zone of normal human skin and basal cell carcinoma. J Invest Dermatol 98: 864-870, 1992.

62. Chopra A, Maitra B and Korman NJ: Decreased mRNA expression of several basement membrane components in basal cell carcinoma. J Invest Dermatol 110: 52-56, 1998.

63. Nievers MG, Schaapveld RQ and Sonnenberg A: Biology and function of hemidesmosomes. Matrix Biol 18: 5-17, 1999.

64. Jones PH, Harper S and Watt FM: Stem cell patterning and fate in human epidermis. Cell 80: 83-90, 1995.

65. Hall PA and Watt FM: Stem cells: the generation and maintenance of cellular diversity. Development 106: 619-633, 1989.

66. Rousselle P, Lunstrum GP, Keene DR and Burgeson RE: Kalinin: an epithelium-specific basement membrane adhesion molecule that is a component of anchoring filaments. J Cell Biol 114: 567-576, 1991 .

67. Mainiero F, Murgia C, Wary KK, Curatola AM, Pepe A, Blumemberg M, Westwick JK, Der ChJ and Giancotti FG: The coupling of $\alpha 634$ integrin to Ras-MAP kinase pathways mediated by Shc controls keratinocyte proliferation. EMBO J 16: 2365-2375, 1997.

68. Guo W and Giancotti FG: Integrin signaling during tumor progression. Nat Rev Mol Cell Biol 5: 816-826, 2004.

69. Murgia C, Blaikie P, Kim N, Dans M, Petrie HT and Giancotti FG Cell cycle and adhesion defects in mice carrying a targeted deletion of the integrin 34 cytoplasmic domain. EMBO J 17: 3940-3951, 1998

70. Di Persio CM, van der Neut R, Georges-Labouesse E, Kreidberg JA, Sonnenberg A and Hynes RO: $\alpha 3 \beta 1$ and $\alpha 6 \beta 4$ integrin receptors for laminin-5 are not essential for epidermal morphogenesis and homeostasis during skin development. J Cell Sci 113: 3051-3062, 2000

71. Raymond K, Kreft M, Janssen H, Calafat J and Sonnenberg A Keratinocytes display normal proliferation, survival and differentiation in conditional 34 -integrin knockout mice. J Cell Sci 118: 1045-1060, 2005.

72. Owens DM, Romero MR, Gardner C and Watt FM: Suprabasal a6ß4 integrin expression in epidermis results in enhanced tumourigenesis and disruption of TGFß signaling. J Cell Sci 116: 3783-3791, 2003.

73. Tank K, Nie D, Cai Y and Honn KV: The beta 4 integrin subunit rescues A431 cells from apoptosis through a PI-3K/Akt kinase signaling pathway. Biochem Biophys Res Commun 264: 127-132, 1999.

74. Giannelli G, Astigiano S, Antonaci S, Morini M, Barbieri O, Noonan DM and Albini A: Role of the $\alpha 3 \beta 1$ and $\alpha 634$ integrins in tumor invasion. Clin Exp Metastasis 19: 217-223, 2002.

75. Howley PM: Papillomaviridae: the viruses and their replication. In: Virology. Fields BN, Knipe DM and Howley PM (eds). Vol. 2, Lippincott-Raven, Philadelphia, pp2045-2076, 1996. 
76. Shah KV and Howley PM: Papillomaviridae: the viruses and their replication. In: Virology. Fields BN, Knipe DM and Howley PM (eds). Vol. 2. Lippincott-Raven, Philadelphia, pp2077-2109, 1996.

77. Evander M, Frazer IH, Payne E, Qi YM, Hengst K and McMillan NA: Identification of the alpha 6 integrin as a candidate receptor for papillomaviruses. J Virol 71: 2449-2456, 1997.

78. Jablonska S, Majewski S and Obalek S: Cutaneous warts. Clin Dermatol 15: 181-198, 1997.

79. Fuchs PG, Horn S, Iftner T, May M, Stubenrauch F and Pfister $\mathrm{H}$ : Molecular biology of epidermodysplasia verruciformisassociated human papillomaviruses. In: Virus Strategies. Molecular Biology and Pathogenesis. Doerfler W and Boehm P (eds). Verlag Chemie, Weinheim, pp517-529, 1993.

80. Pfister $\mathrm{H}$ and ter Schegget J: Role of HPV in cutaneous premalignant and malignant tumors. Clin Dermatol 15: 335-347, 1997.

81. Matsukura T and Sugase M: Identification of genital human papillomaviruses in cervical biopsy specimens: segregation of specific virus types in specific clinicopathologic lesions. Int $\mathbf{J}$ Cancer 61: 13-22, 1995.

82. Bosch FX and de Sanjosé S: Human papillomavirus and cervical cancer-burden and assessment of causality. J Natl Cancer Inst Monogr 31: 3-13, 2003.

83. Shiffman M and Krüger-Kjaer S: Natural history of anogenital human papillomavirus infection and neoplasia. J Natl Cancer Inst Monogr 31: 14-19, 2003.
84. Sashiyama H, Shino Y, Sakao S, Shimada H, Kobayashi S, Ochiai T and Shirasawa H: Alteration of integrin expression relates to malignant progression of human papillomavirusimmortalized esophageal keratinocytes. Cancer Lett 177: 21-28, 2002.

85. Williams AT, Sexton CJ, Hanna NF and Leigh IM: Up-regulation of integrin expression in benign vulvar warts. J Pathol 175: 311-317, 1995.

86. Aplin JD, Dawson S and Seif MW: Abnormal expression of integrin alpha 6 beta 4 in cervical intraepithelial neoplasia. Br J Cancer 74: 240-245, 1996.

87. Carico E, French D, Bucci B, Falcioni R, Vecchione A and Mariani-Costatntini R: Integrin beta 4 expression in the neoplastic progression of cervical epithelium. Gynecol Oncol 49: 61-66, 1993

88. Daniel B, Rangarajan A, Mukherjee G, Vallikad E and Kriszna S: The link between integration and expression of human papillomavirus type 16 genome and cellular changes in the evolution of cervical intraepithelial neoplastic lesions. J Gen Virol 78: 1095-1101, 1997.

89. Corden SA, Sant-Cassia LJ, Easton AJ and Morris AG: The integration of HPV-18 DNA in cervical carcinoma. Mol Pathol 52: 275-282, 1999.

90. Oldak M, Smola H, Aumailley M, Rivero F, Pfister H and Smola-Hess S: The human papillomavirus type 8 E2 protein suppresses B4 integrin expression in primary human keratinocytes. J Virol 78: 10738-10746, 2004. 